\title{
HUBUNGAN USIA, PARITAS DAN PENGETAHUAN IBU NIFAS TERHADAP PERAWATAN PAYUDARA DI PUSKESMAS SUNGAI DURIAN TAHUN 2021
}

\author{
Telly Katharina ${ }^{1}$, Lisnawati² ${ }^{2}$ Ribka Laoly ${ }^{3}$ \\ Akademi Kebidanan Panca Bhakti Pontianak \\ Email korespondensi : akbidpbpontianak@gmail.com
}

\begin{abstract}
ABSTRAK
Masa nifas (puerperium) dimulai sejak 2 jam setelah lahirnya plasenta sampai dengan 6 minggu (42 hari) setelah itu. Perawatan payudara adalah suatu tindakan untuk merawat payudara terutama pada masa nifas (masa menyusui) untuk memperlancarkan pengeluaran ASI. Berdasarkan data yang didapat dari Puskesmas Sungai Durian Tahun 2021 masih banyak ibu nifas yang belum mengetahui perawatan payudara dan pengetahuan ibu nifas tentang perawatan payudara masih kurang. Metode penelitian yang digunakan peneliti adalah analitik korelasi yaitu suatu metode untuk menganalisis hubungan antara dua variabel atau lebih dan menghubungkan ke dua variabel dengan pengujian hipotesis, dengan pendekatan cross sectional. Populasi dalam penelitian ini adalah seluruh ibu nifas yang ada di Puskesmas Sungai Durian Tahun 2021 dengan sampel 30 orang. Alat ukur yang digunakan dalam pengumpulan data adalah kuesioner. Hasil penelitian ini dari 30 responden tentang perawatan payudara di dapatkan hasil bahwa sebagian besar responden yaitu 18 orang $(60.0 \%)$ melakukan perawatan payudara, hampir seluruh responden yaitu 24 orang $(80.0 \%)$ berusia 20-30 tahun, sebagian besar responden yaitu 17 orang (56.7\%) multipara, sebagian dari responden yaitu 14 orang $(56,7 \%)$ berpengetahuan baik tentang perawatan payudara, dan analisis bivariat adalah tidak ada hubungan antara usia dengan perawatan payudara dengan hasil $p$-value $1.000>0,05$, tidak ada hubungan antara paritas dengan perawatan payudara dengan hasil p-value $0,627>0,05$, dan tidak ada hubungan antara pengetahuan dengan perawatan payudara dengan hasil $p$-value $0.200>0,05$. Saran yang diberikan dari penelitian ini agar para tenaga kesehatan dapat memberikan informasi tentang perawatan payudara melalui penyuluhan dan adanya poster diruangan perawatan ibu nifas tentang cara perawatan payudara
\end{abstract}

\section{Kata Kunci : Ibu Nifas, Usia, Pengetahuan, Paritas, Perawatan Payudara}

\begin{abstract}
The postpartum period (puerperium) begins 2 hours after the birth of the placenta up to 6 weeks (42 days) after that. Breast care is an action to treat the breast, especially during postpartum (breastfeeding) to facilitate the production of breast milk. Based on data obtained from the Puskesmas Sungai Durian in 2021, there are still many nifas mothers who do not know breast care and maternal knowledge about breast care is still lacking. The research method used by researchers is correlation analytics., with a cross sectional approach. The population in this study is all nifas mothers in the Puskesmas Sungai Durian in 2021 with a sample of 30 people. The measuring instrument used in data collection is a questionnaire. The results of this study from 30 respondents on breast care were obtained that most respondents were 18 people (60.0\%) doing breast care, almost all respondents were 24 people (80.0\%) aged 20-30 years, Most respondents were 17 people (56.7\%) multipara, some of the respondents were 14 people $(56.7 \%)$ knowledgeable about breast care, and bivariate analysis is that there is no relationship between age and breast care with a p-value of 1,000 $>0.05$, there is no association between parity and breast care with a p-value of $0.627>0.05$, and there is no association between knowledge and breast care with a p-value of $0.200>0.05$. Advice given from this study so that health workers can provide information about breast care through counseling and the existence of posters in the mother's care room about how to care for breasts.
\end{abstract}

Keywords : mother nifas, age, knowledge, parity, breast care

\footnotetext{
${ }^{1}$ Dosen Akademi Kebidanan Panca Bhakti Pontianak

${ }^{2}$ Dosen Akademi Kebidanan Panca Bhakti Pontianak

${ }^{3}$ Mahasiswa Akademi Kebidanan Panca Bhakti Pontianak
} 


\section{Pendahuluan}

Perawatan payudara adalah perawatan payudara setelah ibu melahirkan dan menyusui yang merupakan suatu cara yang dilakukan untuk merawat payudara agar air susu keluar dengan lancar. Perawatan payudara sangat penting dilakukan selama hamil sampai masa menyusui. Hal ini dikarenakan payudara merupakan satu-satu penghasil ASI yang merupakan makanan pokok bayi yang baru lahir sehingga harus dilakukan sedini mungkin (Walyani, 2017).

Tujuan perawatan payudara adalah untuk memelihara hygiene payudara, melenturkan dan menguatkan puting susu, payudara yang terawat akan memproduksi ASI cukup untuk kebutuhan bayi, dengan perawatan payudara yang baik puting susu tidak akan lecet sewaktu di hisap oleh bayi, melancarkan aliran ASI, mengatasi puting susu datar atau terbenam supaya dapat dikeluarkan sehingga siap disusukan kepada bayinya (Walyani, 2017).

Ibu yang tidak melakukan perawatan payudara dapat berakibat menjadi masalah pada payudara yaitu pengeluaran ASI tidak lancar, puting susu tidak menonjol, produksi ASI sedikit, bendungan payudara, mastitis dan abses payudara. Dengan melakukan perawatan payudara yang benar maka ibu nifas dapat terhindar dari infeksi pada payudara sehingga bayi mendapatkan nutrisi yang dibutuhkan (Saryono, 2009).

Menurut data WHO (World Health Organization) terbaru pada tahun 2017 persentase perempuan menyusui yang mengalami bendungan ASI rata-rata mencapai 65,12\% atau sebanyak 7342 ibu nifas, pada tahun 2016 ibu yang mengalami bendungan ASI sebanyak 6823 orang dan pada tahun 2017 terdapat ibu yang mengalami bendungan ASI sebanyak 6543 orang dari 8.741 orang (Awaliyah, 2019).

Menurut data ASEAN tahun 2016 disimpulkan bahwa persentase cakupan kasus bendungan ASI pada ibu nifas tercatat 107.654 ibu nifas, pada tahun 2016 terdapat ibu nifas yang mengalami bendungan ASI sebanyak 95.698 orang, serta pada tahun 2017 ibu yang mengalami bendungan ASI sebanyak 76.543 orang. Hal ini disebabkan karena kesadaran masyarakat dalam mendorong peningkatan pemberian ASI masih relatif rendah (Awaliyah, 2019).

Pemerintah melalui Departemen Kesehatan memberikan kebijakan sesuai dengan dasar kesehatan pada ibu nifas, yakni kunjungan masa nifas minimal 4 kali. Tujuan kebijakan tentang kunjungan nifas yaitu untuk menilai keadaan ibu dan bayi baru lahir, dan untuk mencegah, mendeteksi dan menangani masalah yang terjadi (Rukiyah \& Yulianti, 2018).

Peran bidan dalam masa nifas diantaranya adalah memberikan KIE tentang perawatan payudara, memberikan panyuluhan kepada ibu nifas agar tetap menjaga kesehatan payudara yang bertujuan agar dapat mengurangi dan mengatasi masalah ASI yang tidak lancar sehingga ibu dapat menyusui bayinya secara eksklusif (Suherni, 2009).

Faktor-faktor yang menyebabkan ibu nifas tidak melakukan perawatan payudara karena kurangnya informasi yang didapat dari tenaga kesehatan, kurangnya pengetahuan ibu nifas tentang manfaat perawatan payudara, kurangnya dukungan dari suami, dan ibu merasa malas melakukan perawatan payudara, serta ibu nifas tidak tahu cara melakukan perawatan payudara (Rustarmadji, 2005).

Kunjungan pelayanan kesehatan ibu nifas yang diberikan di Puskesmas Sungai Durian dilakukan sedikitnya 3 kali yaitu pada 6 jam sampai 3 hari, 4 hari sampai 28 hari, 29 hari sampai 42 hari. Dalam kunjungan pelayanan kesehatan ibu nifas yang diberikan meliputi pemeriksaan kondisi ibu, pemberian kapsul vitamin A, ASI eksklusif, pelayanan kontrasepsi pasca persalinan dan konseling. cakupan kunjungan ibu nifas di Puskesmas Sungai Durian tahun 2020 yaitu KF1 7,73\% KF2 7,73\% KF3 7,73\%.

Berdasarkan latar belakang diatas penulis merasa tertarik untuk mengambil penelitian tentang Hubungan Usia, Paritas Dan Pengetahuan Ibu Nifas Terhadap Perawatan Payudara Di Puskesmas Sungai Durian Tahun 2021 
Metode Penelitian

Desain penelitian ini adalah analitik korelasi dengan pendekatan cross sectional, populasi adalah semua ibu nifas di Puskesmas Sungai

Durian sebanyak 120 orang. Sampel jumlah 30 responden dengan kriteria inklusi dan kriteria eksklusi.

Tabel 1.1 Kategori Perawatan Payudara, Usia, Paritas, dan Pengetahuan Ibu Nifas Di Puskesmas Sungai Durian Tahun 2021

\begin{tabular}{|c|c|c|}
\hline Variabel & Frekuensi & Presentase $(\%)$ \\
\hline \multicolumn{3}{|l|}{ Umur } \\
\hline 20-30 tahun & 25 & 83.3 \\
\hline$>30$ tahun & 5 & 16.7 \\
\hline \multicolumn{3}{|l|}{ Paritas } \\
\hline Primipara & 12 & 40,0 \\
\hline Multipara & 18 & 60,0 \\
\hline \multicolumn{3}{|l|}{ Pengetahuan } \\
\hline Baik & 14 & 46,7 \\
\hline Cukup & 4 & 13,3 \\
\hline Kurang & 12 & 40,0 \\
\hline \multicolumn{3}{|l|}{ Perawatan Payudara } \\
\hline Melakukan & 18 & 60.0 \\
\hline Tidak melakukan & 12 & 40.0 \\
\hline Total & 30 & 100 \\
\hline
\end{tabular}

Berdasarkan tabel diatas menunjukkan bahwa sebagian besar responden yaitu 18 orang $(60.0 \%)$ melakukan perawatan payudara dan sebagian dari responden yaitu 12 orang (40.0\%) tidak melakukan perawatan payudara. Berdasarkan umur hampir seluruh responden yaitu 25 orang $(83,3 \%)$ berusia $20-30$ tahun.
Berdasarkan paritas menunjukkan bahwa sebagian besar responden yaitu 18 orang $(60,0 \%)$ adalah multipara dan berdasarkan pengetahuan menunjukkan bahwa sebagian dari responden yaitu 14 orang $(46,7 \%)$ berpengetahuan baik tentang perawatan payudara.

Tabel 1.2 Hubungan Usia, Paritas dan Pengetahuan Dengan Perawatan Payudara Di Puskesmas Sungai Durian Tahun 2021

\begin{tabular}{|c|c|c|c|c|c|}
\hline \multirow[t]{2}{*}{ Variabel } & \multicolumn{4}{|c|}{ Perilaku perawatan payudara } & \multirow[t]{2}{*}{ p-value } \\
\hline & Melakukan & $\%$ & Tidak Melakukan & $\%$ & \\
\hline \multicolumn{6}{|c|}{ Umur } \\
\hline 20-30 tahun & 11 & 36,7 & 14 & 46,7 & 1,000 \\
\hline$>30$ tahun & 1 & 3,3 & 4 & 13,3 & \\
\hline \multicolumn{6}{|c|}{ Paritas } \\
\hline Primipara & 6 & 20.0 & 6 & 20.0 & 0.627 \\
\hline Multipara & 6 & 20.0 & 12 & 40.0 & \\
\hline \multicolumn{6}{|c|}{ Pengetahuan } \\
\hline Baik & 8 & 26,7 & 6 & 20,0 & 0,200 \\
\hline Cukup & 1 & 3,3 & 3 & 10,0 & \\
\hline Kurang & 3 & 10,0 & 9 & 30,0 & \\
\hline
\end{tabular}

Hasil analisis bivariat didapatkan nilai $p$-value $0,627>0,05$. Maka dengan ini tidak ada hubungan antara paritas dengan perawatan payudara. Hasil analisis bivariat didapatkan nilai $p$-value $0,200>0,05$. Maka tidak ada hubungan antara pengetahuan dengan perawatan payudara.

\section{Pembahasan}

Univariat

Berdasarkan hasil penelitian didapatkan hasil bahwa sebagian besar responden yaitu 18 
orang $(60.0 \%)$ melakukan perawatan payudara. Berdasarkan usia hampir seluruh responden yaitu 25 orang ( $83.3 \%$ ) berusia 20 30 tahun. Berdasarkan paritas menunjukkan bahwa sebagian dari responden yaitu 17 orang (56,7\%) adalah multipara dan berdasarkan pengetahuan menunjukkan bahwa sebagian dari responden yaitu 14 orang $(46,7 \%)$ berpengetahuan baik tentang perawatan payudara.

Usia adalah umur individu yang terhitung mulai dari saat dilahirkan sampai berulang tahun. Semakin cukup umur, tingkat kematangan dan kekuatan seseorang akan lebih matang dalam berfikir dan bekerja. Kepercayaan masyarakat seseorang lebih dewasa dipercaya dari orang yang belum tinggi kedewasaannya. Hal ini akan sebagai dari pengalaman dan kematangan jiwa (Elisabeth dalam Wawan dan Dewi, 2010).

Usia seorang wanita pada saat masa nifas sebaiknya tidak terlalu muda dan tidak terlalu tua. Umur yang kurang dari 20 tahun atau lebih dari 35 tahun, seorang perempuan butuh kesiapan untuk menghadapi proses setelah ia melahirkan khususnya di masa nifas karena masa nifas adalah masa menyusui, masa menyusui membutuhkan kesiapan fisik, emosi, psikologi, sosial dan ekonomi (Ruswana, 2006).

Ibu yang terlalu sering melahirkan mempunyai resiko bagi kesehatannya dan bayinya karena pada ibu timbul kerusakan pembuluh darah dinding uterus yang mempengaruhi sirkulasi nutrisi ke janin, dapat membedakan atau memisahkan, mengelompokkan, membuat diagram (bagan) terhadap pengetahuan atas objek tersebut, sintesis (synthesis) menunjukkan suatu kemampuan seseorang untuk merangkum atau meletakkan dalam satu hubungan yang logis dari komponen-komponen pengetahuan yang dimiliki. Dengan kata lain, sintesis adalah suatu kemampuan untuk menyusun formulasi baru dari formulasi-formulasi yang telah ada, evaluasi (evaluation) berkaitan dengan kemampuan seseorang untuk melakukan justifikasi atau penilaian terhadap suatu objek tertentu. Penilaian ini dengan sendirinya didasarkan pada suatu kriteria yang ditentukan sendiri atau norma-norma yang berlaku di masyarakat (Notoatmodjo, 2010). dimana jumlah nutrisi akan berkurang sehingga dapat menyebabkan gangguan pertumbuhan dan perkembangan janin yang kelak akan lahir dengan BBLR (Manuaba, 2008). Jumlah paritas dari responden juga dapat mempengaruhi tingkat pengetahuannya. Semakin banyak jumlah anak yang dilahirkan, semakin beragam pula pengalaman dan informasi yang diperoleh oleh ibu (Nursalam, 2005).

Pengetahuan seseorang terhadap objek mempunyai intensitas atau tingkat yang berbeda-beda. Secara garis besarnya dibagi dalam 6 tingkat pengetahuan, yaitu : tahu (know) diartikan sebagai recall (memanggil) memori yang telah ada sebelumnya setelah mengamati sesuatu, memahami (comprehension) suatu objek bukan sekedar tahu terhadap objek tersebut, tidak sekedar dapat menyebutkan, tetapi orang tersebut dapat menginterpretasikan secara benar tentang objek yang diketahui tersebut, aplikasi (application) diartikan apabila orang yang telah memahami objek yang dimaksud dapat menggunakan atau mengaplikasikan prinsip yang diketahui tersebut pada situasi yang lain, analisis (analysis) adalah kemampuan seseorang untuk menjabarkan atau memisahkan, kemudian mencari hubungan antara komponen-komponen yang terdapat dalam suatu masalah atau objek yang diketahui. Indikasi bahwa pengetahuan seseorang itu sudah sampai pada tingkat analisis adalah apabila orang tersebut telah

\section{Analisis Bivariat}

a. Hubungan Usia Dengan Perilaku
Perawatan Payudara

Hasil analisis $\mathrm{p}$ value $1,000>0,05$, artinya nilai tersebut lebih besar dari 0,05 . Dengan demikian dapat disimpulkan bahwa tidak ada hubungan antara usia dengan perawatan payudara.

Tidak adanya hubungan antara usia dan perawatan payudara karena pada penelitiaan ini umur 20-30 tahun dan umur $>30$ tahun termasuk pada kelompok umur yang telah memiliki kematangan fisik maupun emosional. Sehingga pada usia ini lebih mudah menerima dan mencerna informasi yang didapat atau yang diberikan.

Dengan adanya usia yang telah matang untuk menjadi seorang ibu maka secara 
psikologis bisa lebih menerima proses kehamilan dan akan berhati-hati saat hamil sampai bersalinnya, lebih tanggap terhadap perubahan, lebih bisa menyerap beragam informasi yang penting tentang hal yang berhubungan dengan perilaku perawatan payudara pada ibu nifas. Dengan adanya umur yang ideal tersebut diharapkan secara jasmani, rohani psikologis ibu nifas mampu meminimalisir beragam perubahan fisiologisnya yang terjadi dari hamil sampai nifas termasuk perilaku perawatan payudara pada ibu nifas.Melahirkan anak pada usia ibu yang muda $(<20$ tahun) atau terlalu tua $(35$ tahun) mengakibatkan kualitas janin/anak yang rendah dan juga akan merugikan kesehatan ibu. Karena ibu yang terlalu muda ( $<20$ tahun) bisa terjadi kekurangpahaman dalam merawat payudara sehingga berakibat ASI yang dikeluarkan kurang lancar, jumlah yang dikeluarkan tidak maksimal. Usia yang paling baik yaitu lebih dari 20 tahun dan kurang dari 35 tahun. Semakin cukup umur, tingkat kematangan dan kekuatan seseorang akan lebih matang berfikir dan bekerja.

b. Analisis Hubungan Paritas Dengan Perilaku Perawatan Payudara

Hasil analisis p value 0,627 >0,05, artinya nilai tersebut lebih besar dari 0,05 . Dengan demikian dapat disimpulkan bahwa tidak ada hubungan antara paritas dengan perawatan payudara.

Tidak adanya hubungan antara paritas dan perawatan payudara pada penelitian ini karena masih banyak ibu nifas yang berstatus

\section{Daftar Pustaka}

Ade Ayu Prawita \& Marda Salima. 2018. Hubungan Pengetahuan Dan Sikapibu Nifas Tentang Perwatan Payudara Dan Pelaksanaan Perawatan Payudara. http://ejournal.helvetia.ac.id/index.php/j bk/article/ view/399. Diakses 16 Agustus 2021, 13:00 WIB.

Ani Nur Fauziah \& Danar Lestyawati. 2012. Gambaran Sikap Ibu Nifas Tentang

Perawatan Payudara. https://jurnal.stikesmus.ac.id/ index.php/JKebIn/article. Diakses 9 Juni 2021, 11:00 WIB multipara tidak melakukan perawatan payudara sama halnya dengan ibu nifas yang berstatus primipara masih banyak yang belum melakukan perawatan payudara.

c. Analisis Hubungan Pengetahuan Dengan Perilaku Perawatan Payudara

Hasil analisis $p$ value $0,200>0,05$, artinya nilai tersebut lebih besar dari 0,05 . Dengan demikian dapat disimpulkan bahwa tidak ada hubungan antara pengetahuan dengan perawatan payudara.

Tidak adanya hubungan antara pengetahuan dengan perawatan payudara pada penelitian ini karena masih ada ibu nifas yang berpengetahuan baik tetapi tidak melakukan perawatan payudara.

Pengetahuan adalah hasil "tahu" dan ini terjadi setelah orang mengadakan penginderaan terhadap suatu objek tertentu. Penginderaan terhadap objek terjadi melalui panca indera manusia melalui penglihatan, pendengaran, penciuman, rasa dan raba dengan sendiri. Sebagian besar pengetahuan diperoleh melalui mata dan telinga (Notoatmodjo, 2010).

\section{Kesimpulan}

a. Tidak ada hubungan antara usia dengan perawatan payudara

b. Tidak ada hubungan antara paritas dengan perawatan payudara

c. Tidak ada hubungan antara pengetahuan dengan perawatan payudara.

AO Harefa, 2018. Pengetahuan Ibu Nifas Tentang Perawatanpayudara Dengan Bendungan Asi Di Klinik Pratama Sejati.

http://repository.helvetia.ac.id/1023/3/B

AB\%20IV-V.pdf. Diakses 17 Juni 2021, 15:00 WIB.

Agung Wibowo J, 2017. Pengaruh Pendidikan Kesehatan Terhadap Pengetahuan Tentang Perawatan Payudara Masa Nifas Pada Ibu Hamil Trimester III Di Puskesmas Pajang Surakarta, Program Studi S1 Keperawatan Fakultas Ilmu Kesehatan Universitas Muhammadiyah Surakarta. 
Arikunto, Suharsimi. 2010. Prosedur Penelitian Suatu Pendekatan Praktik. Jakarta: Rinek Cipta.

Awaliyah, Aenul Fitriani. 2019. Gambaran Pengetahuan Ibu Nifas Usia Remaja Tentang Perawatan Payudara. http://repository.

ummat.ac.id/60/1/COVER\%20-

\%20BAB\%20III.pdf. Diakses: 8 Maret 2021, 20:00 WIB.

Barni \& Dewie Sulistyorini. 2019. Konsep Lokal Tentang Perawatan Payudara. https://ejournal.poltektegal.ac.id/index. php/siklus/article/view/1363. Diakses: 28 Maret 2021, 21:00 WIB

Dewi, Vivian Nanny Lia \& tri sunarsih. 2013. Asuhan Kebidanan Pada Ibu Nifas. Jakarta: Salemba Medika.

Desi Ratnasari. 2014. Gambaran Tingkat Pengetahuan Ibu Nifas Tentang Perawatan Payudara. http://repository.unjaya.ac.id/1984/2/De si\%20 Ratnasari_1311065_full.pdf. Diakses 12 Juni 2021, 11:00 WIB

Dinkes Kalimantan Barat. 2017. Data Kesehatan Provinsi Kalimantan Barat 2017.

https://dinkes.kalbarprov.go.id/wpcontent/uploads/2019/04/data-daninformasi-2017.pdf. Diakses 27 Juni 2021, 15:00 WIB.

BKKBN. 2006. Deteksi Dini Komplikasi Persalinan. Jakarta: BKKBN

Fitriani. 2013. Gambaran Pengetahuan Ibu Hamil Tentang Perawatan Payudara Selama Kehamilan Dan Pada Masa Nifas. $\quad$ http://repositori.uinalauddin.ac.id/3169/1/fitriani.pdf. Diakses: 10 Maret 2021, 19:00 WIB.

Hidayat, A, 2011. Metode Penelitian Keperawatan Dan Teknik Analisis Data. Jakarta: Selemba Medika.

Irma, Wahyuni. 2017. Gambaran Tingkat Pengetahuan Ibu Nifas Tentang Perawatan Payudara. http://repository.unjaya.ac.id/2212/2/ir ma\%20

wahyuni_1114027_1114027_pisah.pdf. Diakses: 8 Juni 2021, 20:00 WIB

Mangumpaus, Adelvia Heppy \& Maryati Tatangindatu, Jelita Hinonaung. 2017. Gambaran Pengetahuan Ibu Nifas Tentang Perawatan Payudara
DiWilayah Kerja Puskesmas Kuma. Http://E-

Journal.Polnustar.Ac.Id/Jis/Article/Vie w/28. Diakses: 26 April 2021, 20:00 Wib

Manuaba. 2008. Ilmu Kebidanan, Kandungan dan KB. Jakarta: EGC

Maritalia, Dewi. 2017. Asuhan Kebidanan Pada Ibu Nifas. Yogyakarta: Gosyen Publishing.

Marmi. 2015. Asuhan Kebidanan Pada Masa Nifas Puerperium Care. Penerbit Pustaka Belajar. Yogyakarta.

Mutmainah. 2015. Hubungan Tingkat Pengetahuan Tentang Breast Care Dengan Perilaku Breast Care. http://digilib.unisayogya.ac.id/95/1/ NASKAH\%20PUBLIKASI_MUTMAI NAH_201410104007.pdf. Diakses 20 Agustus 2021, 10:00 WIB.

Modul Midwifery Update, Buku Acuan Midwifery Update, 2016, Pengurus Pusat Ikatan Bidan Indonesia (IBI) Jakarta.

Ningsih, Riri.P. 2017. Hubungan Paritas dan Pengetahuan Tentang Imunisasi Tetanus Toxoid Dengan Kelengkapan Imunisasi Tetanus Toxoid Pada Ibu Hamil Trimester III Di Puskesmas Plus Mandiangin Bukit Tinggi Tahun 2017. Keperawatan.Fakultas Ilmu Keperawatan. Sekolah Tinggi Ilmu Kesehatan Perintis.

Notoatmodjo, S. 2003. Metodologi Penelelitian Kesehatan. Rineka Cipta: Jakarta.

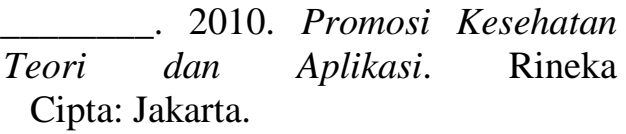

Rukiyah, Ai Yeyeh \& Yulianti, Lia. 2018. Asuhan Kebidanan Pada Ibu Masa Nifas. CV.Trans Info media.

Rustarmadji. 2005. Asuhan Kebidanan Masa Nifas. Yogyakarta: Nuha Medika.

Saryono, Ari Setiawan. 2011. Metodologi Penelitian Kebidanan DIII, DIV, S1 Dan $S 2$. Yogyakarta: Nuha Medika.

Saryono \& Roischa Dyah Permatasari. 2009. Perawatan Payudara. Yogyakarta: Mitra Cendikia.

Suci Dewi Citrawati, Hery Ernawati \& Metti Verawati. 2020. Hubungan Pengetahuan Ibu Post Partum Dengan 
Perilaku Perawatan Payudara. http://studentjournal.umpo.ac.id/index.p $\mathrm{hp} / \mathrm{HSJ} /$ article/download/60/298. Diakses 10 Juni 2021, 11:30 WIB

SDGs. 2016. Kesehatan Dalam Kerangka Sustainable Development Goals (SDGs). Jakarta: http://sdgs.bappenas.go.id/wpcontent/uploads/2017/09/KesehatanDalam-Kerangka-SDGs.pdf Diakses: 10 Maret 2021, 19:00 WIB.

Suherni. 2009. Perawatan Masa Nifas. Yogyakarta: Fitramaya

Sujarweni, Wiratna. 2014. Metodologi Penelitian Keperawatan. Yogyakarta: Gava Media.

Sulistyawati \& Ary. 2009. Asuhan Kebidanan Pada Ibu Nifas. Yogyakarta: ANDI.

Susila \& Suyanto. 2014. Metode Penelitian Cross Sectional. Sendengngebong, Danguran, Klaten Selatan. Bossscript.

Sutanto, Andina Vita. 2018. Asuhan Kebidanan Nifas dan Menyusui. Yogyakarta: Pustaka Baru Pres.

Sri Wulan, Rahmad Gurusinga. 2012. Pengaruh Perawatan Payudara (Breast Care) Terhadap Volume Asi Pada Ibu Post Partum (Nifas) Di Rsud Deli Serdang Sumut. STIKes Medistra Lubuk Pakam.
Umi, Mey Cahyani, Sugeng Maryanto \& Luvi Dian Afriyani. 2014. Gambaran Tingkat Pengetahuan Dan Karakteristik Ibu Nifas Tentang Perawatan Payudara. http://ejournalnwu.ac.id/article/view/14 35891494. Diakses 9 Juni 2021, 10:00 WIBVarney. 2006. Buku Ajar Asuhan Kebidanan. Jakarta. EGC

Walyani Siwi, Elisabeth. 2017. Asuhan Kebidanan Masa Nifas Dan Menyusui. Yogyakarta: Pustakabarupress.

Yunik Windarti, Uke Maharani Dewi, 2018. Pengaruh Paritas Dan Media Konseling Masa Nifas Terhadap Kemampuan Perawatan Mandiri Ibu Post Partum Di BPM Vivi Surabaya. Fakultas Keperawatan dan Kebidanan Universitas Nahdlatul Ulama Surabaya, Jln. Smea 57 Surabaya Email: yunikwinda@unusa.ac.id 